\title{
Useful Techniques for Artificial Fertilization of the Ommastrephid Squid Illex argentinus
}

\author{
Mitsuo SAKAI ${ }^{1 *}$, Norma E. BRUNETTI ${ }^{2}$, Marcela L. IVANOVIC ${ }^{2}$, \\ Beatriz ELENA ${ }^{2}$ and Yasunori SAKURAI ${ }^{3}$ \\ ${ }^{1}$ National Research Institute of Far Seas Fisheries, Fisheries Research Agency (Yokohama, \\ Kanagawa 236-8648, Japan) \\ ${ }^{2}$ Instituto Nacional de Investigación y Desarrollo Pesquero (INIDEP) (Paseo Victoria Ocampo $\mathrm{N}^{\circ} .1$, \\ 7600 Mar del Plata, Argentina) \\ ${ }^{3}$ Hokkaido University (Hakodate, Hokkaido 041-8611, Japan)
}

\begin{abstract}
This study examined the rate of fertilization in the Argentine shortfin squid Illex argentinus after artificial insemination using sperm from different sources, as well as the effect of cold-storage on the fertilization capacity of gametes from mature squids, and the impact of mechanical agitation on embryonic development. In addition, the process of chorionic expansion during the course of embryonic development was also examined. High fertilization rates were obtained from spermatophores (76$95 \%$ ) and spermatozoa from the vas deferens (73-87\%), but no fertilization was observed using spermatozoa from testes. Female and male gametes stored at $0^{\circ} \mathrm{C}$ had a high fertilization capacity $(>72 \%)$ within $24 \mathrm{~h}$. Embryos (stages 4 to 17; 3 to $61 \mathrm{~h}$ at $20^{\circ} \mathrm{C}$ ) subjected to mechanical agitation at a critical period (stages 5 to $12 ; 5$ to $20 \mathrm{~h}$ at $20^{\circ} \mathrm{C}$ ) exhibited high mortality and abnormal development. In the course of embryonic development, the chorion expanded four times: once at fertilization and then at developmental stages $15-16,17-21$, and finally at stages $25-27$. The growth rate of the third expansion corresponded with an increase in embryonic body length. To improve the fertilization rate and increase the production of healthy paralarvae in on-board experiments, factors such as the origin of spermatozoa, gamete storage methods, and the handling of fertilized eggs during the critical period should be carefully controlled.
\end{abstract}

Discipline: Fisheries

Additional keywords: chorionic expansion, embryonic mortality, fertilization capacity, sperm origin

\section{Introduction}

Artificial fertilization techniques are useful for producing squid embryos and hatchlings to study the early life history of oceanic ommastrephid species, as these are generally difficult to collect during normal capture surveys, e.g., Illex illecebrosus ${ }^{14}$, Todarodes pacificus ${ }^{20,23}$, Ommastrephes bartramii ${ }^{19}$, Sthenoteuthis oualaniensis ${ }^{19}$, I. argentinus $^{16-18}$, and Dosidicus gigas ${ }^{22,24}$. However, except for T. pacificus, I. illecebrosus, and I. argentinus, the technical constraints associated with conducting experiments at sea have meant that accurate information on the fundamental characteristics of embryonic development and hatching stages of most of these species is not known.

After copulation, mature female I. argentinus retain the spermatangia implanted by males at the base of their gills. While these mated females are well suited for artificial fertilization experiments, they are caught much less frequently than mature unmated females and males in the feeding grounds ${ }^{15}$. Mature I. argentinus males (stages III-V) ${ }^{4}$ are frequently encountered on the Argentine shelf throughout the year ${ }^{5}$.

While I. argentinus are known to store spermatozoa in the genital organs, vas deferens, spermatophores, and testis $^{21}$, the viability of the spermatozoa from these tissues is unknown. In T. pacificus, lower fertilization abil-

*Corresponding author: e-mail sakaimit@affrc.go.jp

Received 14 July 2010; accepted 6 October 2010. 
ity has been observed using spermatozoa from the vas deferens and no ability has been observed using spermatozoa from the testis ${ }^{8,10}$. Since the possibility of sourcing male gametes from different organs of freshly caught squid would likely increase the opportunity of artificial fertilization for offshore species such as I. argentinus, developing methods for the prolonged storage of viable gametes would mean that experiments using offshore species could be conducted in land-based laboratories.

In addition to investigating sources of spermatozoa, other studies have examined aspects related to embryonic development and how to improve the survival of embryos produced at sea. Crawford ${ }^{7}$ demonstrated that chorionic expansion was greater in fertilized Loligo pealei eggs cultured in filtered seawater containing relatively high concentrations of bovine serum albumin (BSA; 0.5\%) than in fertilized eggs cultured at lower BSA concentrations, and also that the development of these embryos was comparable to naturally laid jelly strings. Conversely, the chorion diameters of unfertilized eggs cultured in the presence of $0.5 \% \mathrm{BSA} /$ filtered seawater did not change. In addition, chorionic expansion in embryos cultured in plastic Petri dishes containing seawater with $0.5 \%$ BSA that were not lined with agarose died after 3 or 4 days, suggesting that the environment given by the mixture of proteins and carbohydrates present in BSA and agarose functions in the same way as that of egg jelly in promoting hatching and normal development. Given these findings, we similarly expected that the chorionic expansion would also play an important role in the development of ommastrephiid squids.

The present study therefore aimed to 1) improve current artificial fertilization techniques ${ }^{16}, 2$ ) assess the potential use of gametes that have been stored at $0{ }^{\circ} \mathrm{C}$, and 3 ) obtain a steady supply of fertilized I. argentinus eggs. Specifically, the following factors were examined: 1) fertilization rates using spermatozoa from different sources, 2) the effect of mechanical agitation on embryonic development, and 3) the process of chorionic expansion during embryonic development.

\section{Materials and methods}

Live squid were caught off Argentina with a bottom trawl during several cruises of the R/V Capitan Oca Bal$d a$ of the Instituto Nacional de Investigación y Desarrollo Pesquero (INIDEP) from 1995-1999. Mature males (stages III-V) ${ }^{4}$ and females (stages V-VII) ${ }^{4}$ were selected for the experiments. Unfertilized eggs of I. argentinus for fertilization experiments were obtained from adults using the method of Sakai and Brunetti ${ }^{16}$. Mature eggs were collected from the oviducts near the oviducal gland, and spermatozoa were collected from spermatophores, the vas deferens, and/or testis. Oviducal gland jelly was produced by macerating fresh oviducal glands in seawater collected from depths below $400 \mathrm{~m}$ and filtered through a $0.45-\mu \mathrm{m}$ membrane filter (Millipore Corp., MA), and then immediately adding the jelly to all fertilized eggs (Fig. 1). All experiments were conducted on board and the fertilized eggs were incubated at $20 \pm 0.1^{\circ} \mathrm{C}$ under a constant photoperiod of $16 \mathrm{~L} / 8 \mathrm{D}$. The stages of Sakai et al. ${ }^{17}$ were used to describe embryonic development.

Since the primary sites of spermatozoa storage in male I. argentinus are testis, the vas deferens (spermiduct), spermatophores in Needham's sac ${ }^{21}$, spermatozoa were collected from each of these sites, placed in seawater, and examined under a stereo-microscope (Zeiss, Germany). To determine the fertilization rates achieved using spermatozoa from each site, artificial fertilization using mature eggs obtained from the lower portion of the oviduct in mature females and spermatozoa from mature males was conducted. The fertilization rate was calculated using 100 eggs for each experimental group, with eggs at or beyond stage 4 (the two-cell stage) considered to be fertilized.

To investigate the effect of genital-tract cold storage on the rate of fertilization, entire bodies of 20 mature females (stage $\mathrm{V}$ ) and 20 males (stage $\mathrm{V}$ ) were stored at 0 $\pm 1^{\circ} \mathrm{C}$ (not frozen) for $42 \mathrm{~h}$. Artificial fertilization was then conducted at $0 \mathrm{hr}$ (control) and then after 19, 24, 30, 36 , and $42 \mathrm{~h}$ of cold storage. Fertilized eggs were then incubated at $20^{\circ} \mathrm{C}$ and the rate of fertilization was determined $3 \mathrm{~h}$ after artificial insemination.

To elucidate the effect of mechanical agitation on embryo development, embryos in eight developmental stages, stage 4 ( $2.5 \mathrm{~h}$ after insemination), 5 (4.5 hrs), 10 (7.5 h), 11 (8.5 h), 12 (11.5 h), 13 (23 h), 16 (28 h), and 17 ( $39 \mathrm{~h}$ ), were agitated by drawing them into a syringe, injecting them back into the wall, and recording their mortality over the next $48 \mathrm{~h}$. Nine lots were prepared for each of the eight experimental stages, and for one control, which was not agitated. For each lot, approximately 100 fertilized eggs were placed in a $94 \mathrm{~mm}$ diameter Petri dish. To prevent the eggs from rolling in the dish due to the motion of the ship, the eggs were redistributed into a six-welled microplate (each well was $34.6 \mathrm{~mm}$ in diameter and $17.5 \mathrm{~mm}$ in deep) $3 \mathrm{~h}$ after artificial insemination. The embryos were incubated at $20^{\circ} \mathrm{C}$ in well-oxygenated, filtered seawater and agitated according to the following procedure: eggs or developing embryos in seawater were drawn into a $10 \mathrm{~mL}$ syringe, the inner-tip diameter of which was $2 \mathrm{~mm}$, and then dispensed into the wells of the multi-welled plate. Embryo mortality was considered to 
occur when developing embryos became opaque and/or markedly deformed.

The normal development of embryos and the successful hatching of paralarvae are dependent on chorionic expansion during the course of embryonic development ${ }^{16}$. We therefore measured the chorion diameters in the long axis, embryonic body length (BL), and embryonic mantle lengths (ML) of fertilized eggs incubated at $20^{\circ} \mathrm{C}$ from the time of fertilization to near the hatching stage to the nearest $0.01 \mathrm{~mm}$ under a stereo-microscope.

\section{Results}

\section{Sperm motility and rate of fertilization}

For all stages III-V of male maturity, spermatozoa from the spermatophores were motile in seawater, while

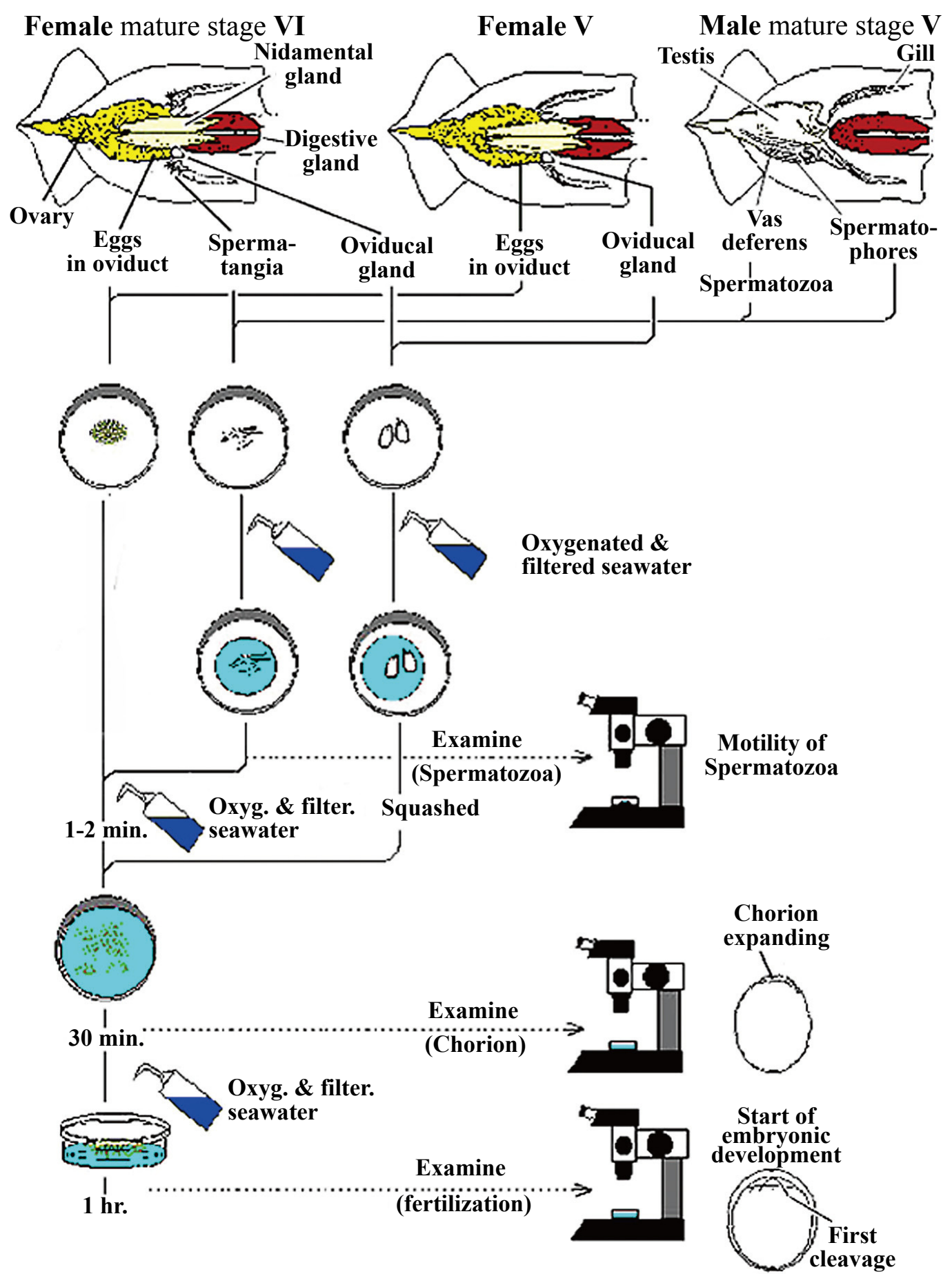

Fig. 1. General procedure for artificial fertilization using a copulated female in stage VI, or a mature female and male in stage $\mathrm{V}$ 
spermatozoa from the vas deferens and testis were immotile. The fertilization rate obtained using spermatozoa from the testis was $0 \%$, while spermatozoa from the vas deferens and spermatophores in stages III-V males were capable of fertilizing eggs. The rate of fertilization achieved with spermatozoa from both the vas deferens and spermatophores appeared to increase gradually with male maturity (Fig. 2). The average rate of fertilization using spermatozoa from the vas deferens of stage III males was $72.8 \%$ ( $\pm 15.0 \mathrm{SD})$, which was slightly, but significantly, lower than that obtained using sperm from the spermatophores $(75.7 \pm 9.7 \% \mathrm{SD}$; t-test, $\mathrm{p}<0.05)$. In stage IV males, the rate increased to $83.0 \pm 6.8 \%$ (SD) for spermatozoa from the vas deferens and $83.7 \%( \pm 11.1$, SD) for spermatozoa from the spermatophores. The difference observed between the sources of spermatozoa and the rate of fertilization in males at stage IV was not significant (t-test, $\mathrm{p}>0.10$ ). The fertilization rate in males at stage $\mathrm{V}$ increased to $86.9 \pm 5.4 \%$ (SD) using spermatozoa from the vas deferens and to $84.8 \pm 6.0 \%$ (SD) for spermatozoa from the spermatophores, with a significant difference observed between sources of spermatozoa (t-test, $\mathrm{p}<0.05)$. Although a slight difference was observed in the rate of fertilization between spermatozoa from the vas deferens or spermatophores, both sources of spermatozoa in stage IV-V males were associated with high rates of fertilization ( $>80 \%$ on average). Despite a slightly lower rate of fertilization observed in stage III males compared to stage IV and V males, spermatozoa from the vas deferens and spermatophores in stage III males resulted in successful fertilization.

Gametes from stage $\mathrm{V}$ females and $\mathrm{V}$ males that had been kept in cold storage could be used for artificial fertilization. For gametes stored at $0^{\circ} \mathrm{C}$ for $24 \mathrm{~h}$, fertiliza-

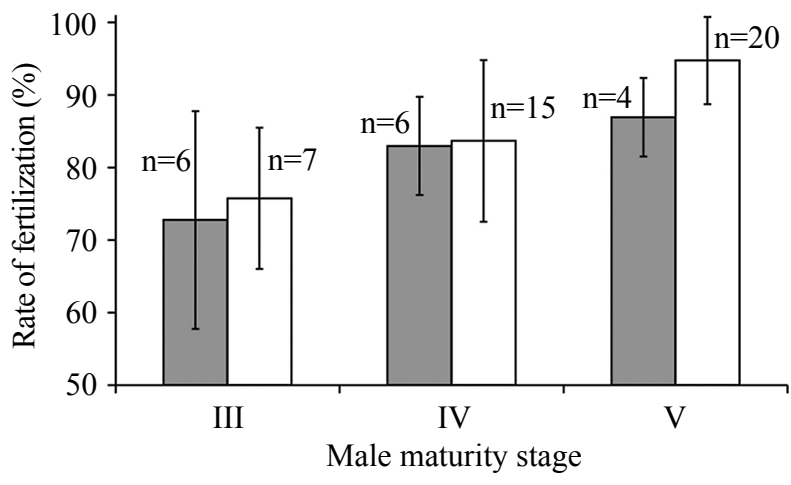

Fig. 2. Fertilization capacity of spermatozoa from the vas deferens and spermatophores from males at maturity stages III, IV, and V

Error bars indicate standard deviation. $\mathrm{n}=$ sample size.

$\square$ : Vas deferens, $\square$ : Spermatophore. tion rates of over $70 \%$ were obtained using spermatozoa from spermatophores (Fig. 3). After 24 h, however, the fertilization capacity decreased markedly. After $30 \mathrm{~h}$, the average rate of fertilization was only $31.1 \%$, and after 40 h, the rate was $0 \%$ (Fig. 3).

\section{Embryonic mortality due to mechanical agitation}

Mechanical agitation of stage 4 embryos (when first cleavage occurs) had only a minor effect on embryonic survival. Cumulative mortality $48 \mathrm{~h}$ after fertilization was less than 19.6\% after agitation (Fig. 4), which was similar to that of the control lot (20.4\%). However, agitation of stage 5 (second cleavage) embryos resulted in high mortality, with cumulative mortality increasing from 20

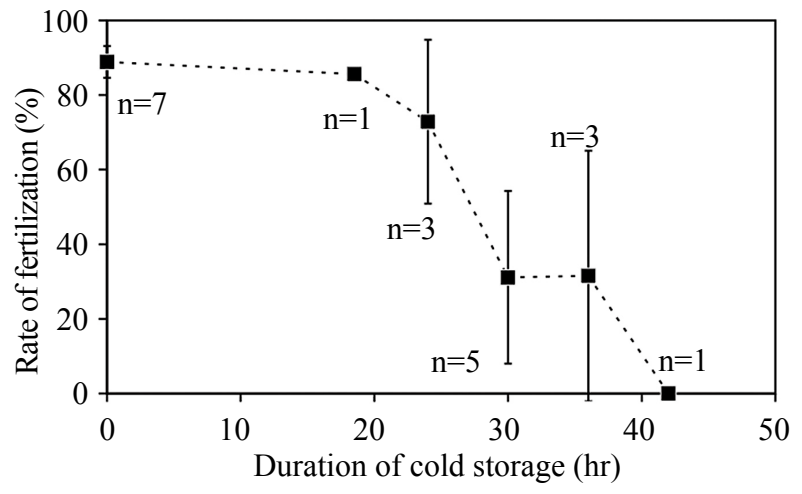

Fig. 3. Influence of cold storage on the fertilization capacity of gametes of mature male and female squid Eggs from mature females in stage $\mathrm{V}$ were inseminated with spermatozoa from male spermatophores in stage V. Error bars indicate standard deviation. $\mathrm{n}=$ sample size.

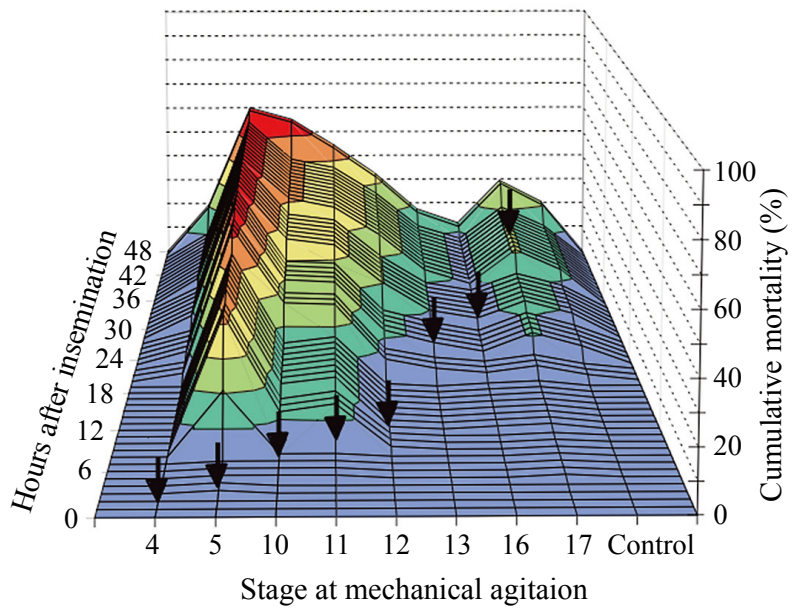

Fig. 4. Cumulative mortality (\%) of developing embryos for $48 \mathrm{~h}$ after fertilization and mechanical agitation applied to each embryonic developmental stage Arrows indicate the time at which mechanical agitation was conducted in each experimental lot. 
to $50 \%$ at 3 to $5 \mathrm{~h}$ after agitation. At $48 \mathrm{~h}$ after the agitation of embryonic stages 5 to 12 , cumulative mortality reached $60 \%$. At embryonic stage 13 , no increase in mortality was observed after agitation, and the cumulative mortality was $17.5 \%$. At embryonic stage 16 (blastoderm reaching the vegetal pole), mortality was very low after agitation, and this low cumulative mortality (11.5\%) was maintained until $48 \mathrm{~h}$ after agitation. Agitation at embryonic stage 17 resulted in a slight increase in mortality, with cumulative mortality after $48 \mathrm{~h}$ reaching approximately $30 \%$. These results indicate that stages 5 to 12 were the most sensitive to mechanical agitation.

\section{Chorion expansion}

Expansion of the chorion occurred four times during embryonic development; first at stages 0 to 10 (20 min after fertilization at $\left.20^{\circ} \mathrm{C}\right)$, then at stages $15-16(48 \mathrm{~h})$, stages 17-21 (72-84 h), and then finally at stages $25-27$ (103-
115 h) (Fig. 5-a). During the first stage of chorionic expansion, the perivitelline space appeared between the vitelline and fertilization membranes. At embryonic stage 4 (approximately $2 \mathrm{~h}$ after fertilization), the perivitelline space developed around the vitelline membrane. The average egg diameter in the long axis increased from $1.01 \pm$ $0.03 \mathrm{~mm}$ (SD) at stage 0 (pre-fertilized egg) to $1.08 \pm 0.02$ $\mathrm{mm}$ (SD) at stage 10 (Fig. 5-b). The first and second chorionic expansions were very gradual, and the average egg diameter reached $1.21 \pm 0.04 \mathrm{~mm}(\mathrm{SD})$ at stage $16(48 \mathrm{~h}$ after fertilization; Fig. 5-b). The third chorionic expansion occurred after stage 17 (Fig. 5-a). Associated with the remarkable expansion seen in this period, which continued until near the hatching stage, the BL of embryos began to increase and the embryos began to revolve slowly in the well-developed perivitelline space. After embryonic stage 21, when the body mantle could just be discerned, ML increased faster than BL. At embryonic
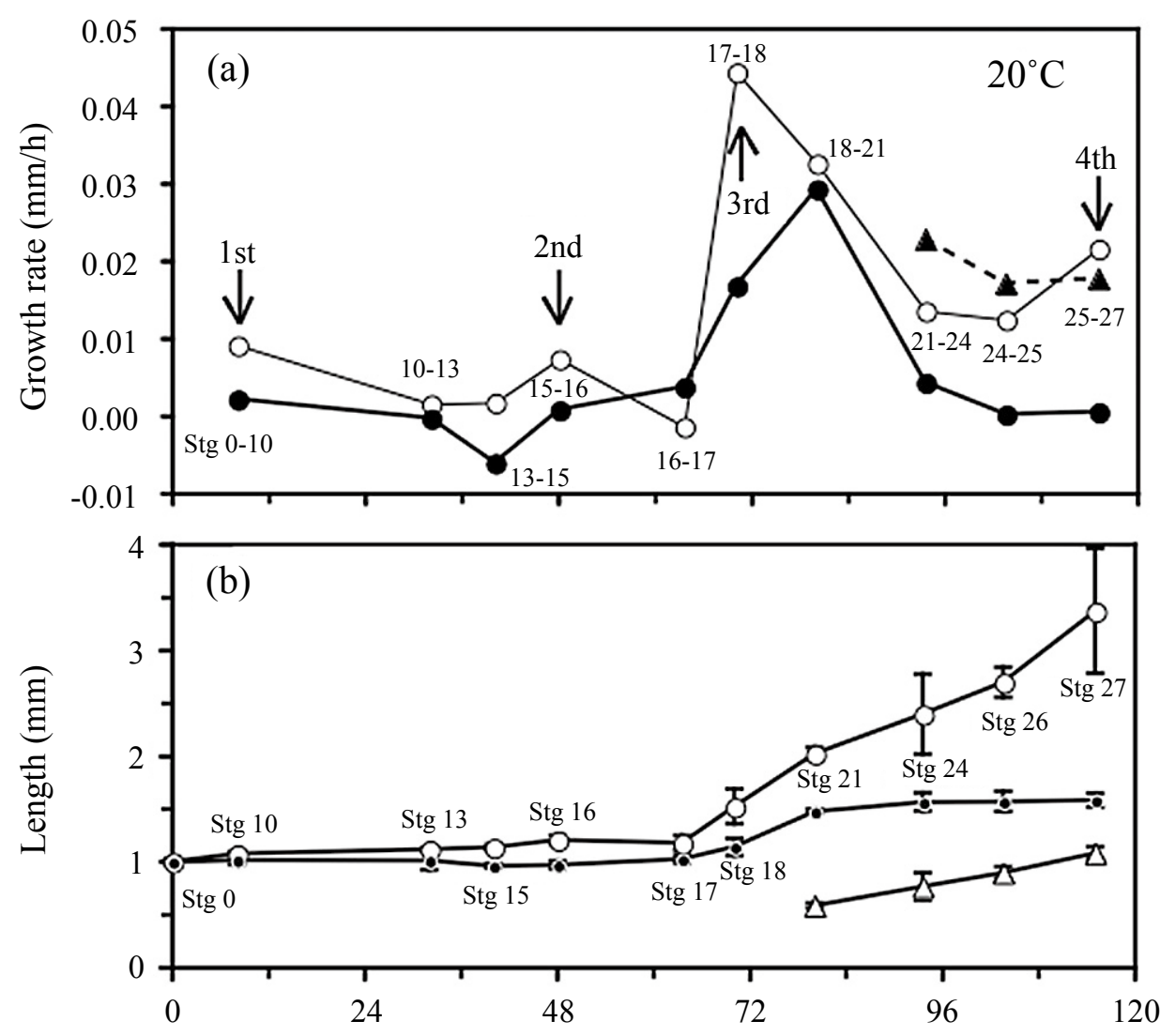

Hours after insemination

Fig. 5. Chorion expansion of artificially fertilized eggs reared at $20^{\circ} \mathrm{C}$

(a) Growth rate $\left(\mathrm{mm} \mathrm{h}^{-1}\right)$ of chorion diameter, body length, and mantle length of embryos reared at $20^{\circ} \mathrm{C}$ during the course of embryonic development. The rate was calculated based on the differences in the length of two stages as indicated. Arrows indicate the first to fourth expansion.

- : Chorion diameter, - : Body length of embryo, $-\mathbf{-}-$ : : Mantle length.

(b) Increase in embryo body length and mantle length. Error bars indicate standard deviation.

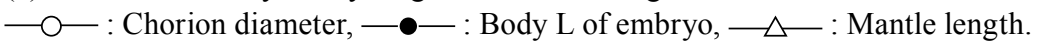


stage 27, the average ML and the chorionic diameter was $1.09 \mathrm{~mm}$ and $3.38 \pm 0.59 \mathrm{~mm}$ (SD), respectively. At a BL of $1.59 \pm 0.07 \mathrm{~mm}(\mathrm{SD})$, the chorionic diameter was approximately twice BL.

\section{Discussion}

A variety of artificial fertilization techniques have recently been established for ommastrephid squids ${ }^{10,11,16,19}$. A common feature of these techniques is not only the methods employed to combine gametes, but also the addition of oviducal gland jelly to the fertilized eggs; the addition of the oviducal gland jelly has been shown to advance chorionic expansion, which is closely related to the normal development of the embryo ${ }^{16}$. When studying offshore species, it is often necessary for artificial fertilization to be conducted at sea, often under unfavorable conditions and far from well-equipped laboratories on land. To ensure the supply of large numbers of hatchlings on a reliable basis, Sakurai et al..$^{19}$ stressed the need to improve methods for obtaining sperm, reducing the incidence of developmental abnormalities, improving chorionic expansion, and preventing infection.

In the present study, immature or immotile spermatozoa from the vas deferens and spermatozoa from the spermatophores of stage $\mathrm{V}$ males were all associated with fertilization rates exceeding 80\% (Fig. 2). However, mean fertilization rates obtained using spermatozoa from the vas deferens and spermatophores of stage III males were $72.6 \%$ and $75.7 \%$, respectively. Ikeda et al. ${ }^{10}$ reported that the rate of fertilization achieved with spermatozoa (likely to be immotile) from the vas deferens was 30.6$50.5 \%$ in $T$. pacificus, whereas the fertilization rate obtained with spermatozoa from spermatophores was 89.9$99.4 \%$; we assume that the maturity of the males used in their study were at stage $\mathrm{V}$ using the scale of Ikeda et al. ${ }^{9}$ for T. pacificus, or stage IV using the scale for I. argenti$n u s^{4}$. It therefore seems that, at the same stages of maturity, the fertilization capacity of spermatozoa from the vas deferens of I. argentinus is higher than that of spermatozoa from the vas deferens of T. pacificus. According to Ikeda et al. ${ }^{10}$, spermatozoa in T. pacificus only become mature after they leave the testes and enter the vas deferens. It is thus possible that the maturation process of spermatozoa in the vas deferens may differ between I. argentinus and T. pacificus. The rate of fertilization of spermatozoa from both the vas deferens and spermatophores in I. argentinus increased gradually after stages III to V (Fig. 2), and spermatozoa from the testis did not fertilize any eggs. Consequently, the fertilization capacity of sperm might not only depend on the site from which the spermatozoa are harvested, but also the stage of squid maturity.

The mechanism of spermiogenesis and the role of the vas deferens, located between the testis and the spermatophoric gland systems in squid, have not yet been investigated in detail and the reason why immotile spermatozoa from vas deferens exhibit some fertilization capacity is not currently clear. In the giant octopus, $O c$ topus dofleini martini, Mann et al. ${ }^{12}$ analyzed changes in the electrolytes of genital-tract fluids and spermatophoric plasma and found that a decrease in potassium and chloride concentrations was accompanied by increased sodium levels as the vesicular spermatophore matured into a prostatic spermatophore as it moved from the testis to the spermatophoric sac through the vas deferens. Indeed, either potassium-cyclic AMP or the osmolarity-calcium system responsible for regulating the feedback mechanism controlling sperm motility ${ }^{13}$ may be related to spermatogenesis in I. argentinus.

Arnold \& O'Dor ${ }^{1}$ reported that the Needham's sac of oceanic squid could be stored cold (not frozen) for several hours in a small dish provided it was covered with seawater. Extending this period further will enable workers to obtain viable spermatozoa from the Needham's sac and improve the ability to conduct artificial fertilization procedures and obtain fertilized eggs. In this study, after 24 $\mathrm{h}$ of cold storage at almost $0^{\circ} \mathrm{C}$, gametes from male and female squid (stage V) could successfully be used for artificial fertilization experiments (Fig. 3). To increase the length of this period over which artificial fertilization experiments can be conducted, we suggest that squid be kept alive under cold anesthesia ${ }^{3}$ before they are used for experiments. Given the many difficulties associated with both rearing squid onboard vessels and in transporting live squid for several days from the site of capture to a laboratory on land, developing a more effective method of storing sperm sources for artificial fertilization needs to be investigated.

In addition, decreasing embryonic mortality rates and the incidence of developmental abnormalities is also important. The agitation test performed in this experiment showed that embryos were extremely sensitive to external mechanical stimuli from the second cleavage (stage 5) to blastoderm formation (stage 12). However, at the time of the first cleavage (stage 4), when the eggs could be judged as being fertilized, and after when the blastoderm began covering the different regions of the eggs (after stage 13), egg mortality was low (Fig. 4). In the squid Loligo pealei, Crawford ${ }^{6}$ demonstrated that cold shock at the stage of the polar body formation could be used to induce polyploidy in this species. Thus, it appears that shock treatment before the first cleavage of the embryo does not cause immediate mortality. On the oth- 
er hand, to reduce embryo mortality after the second cleavage, the embryos should be treated carefully during this critical period as even slight movement of the eggs at this stage can cause a marked decrease in embryonic survival and development. In the case of transferring or separating fertilized eggs between different experimental batches, a procedure gentler than using a pipette is required just before the critical period (stage 5).

Several experimental studies on the role of oviducal gland jelly ${ }^{10,16}$ demonstrated that if the first expansion or perivitelline space were not developed, neither later expansion nor normal embryonic development followed. Thus, despite the magnitude of chorionic expansion observed at stages $0-10$ being very slight, it is a good indicator that subsequent embryonic development will be normal. In this study, the third chorionic expansion (stages 17-18) was relatively marked, with the average diameter of the chorion at developmental stage 27 exceeding 3 $\mathrm{mm}$. Boletzky et al..$^{2}$ also observed a marked expansion of the chorion (to approx. $2 \mathrm{~mm}$ ) in I. coindetii embryos with an ML of $1.4 \mathrm{~mm}$ in eggs spawned in a tank.

We consider that the third chorionic expansion observed in this study has a functional role related to the growth of the body and the ML of the embryo. Chorion diameter increased markedly during the third chorionic expansion (stages 17-21) and coincided with an increase in embryonic BL (Fig. 5-a). The rate of the increase in the diameter of the chorion and in embryonic BL both peaked in stages $17-18\left(0.045 \mathrm{~mm} \mathrm{~h}^{-1}\right)$ and stages $18-21$ $\left(0.029 \mathrm{~mm} \mathrm{~h}^{-1}\right)$, respectively. However, after peaking, no further growth of embryonic BL was observed from stage 25 onward, whereas chorion diameter and ML maintained growth rates of over $0.01 \mathrm{~mm} \mathrm{~h}^{-1}$. During the third chorionic expansion, Sakai et al. ${ }^{17}$ observed that embryos began revolving in the perivitelline space at embryonic stage 18 , occasionally contracting their mantles at stage 24. It appears that having a sufficiently wide perivitelline space is required for this embryo movement. The apparent correlation between the rate of the increase in the diameter of the chorion, as well as BL and ML suggests that a wide perivitelline space is conducive to embryonic growth during organogenesis and the hatching stage. We consider that the third chorionic expansion (stage 17-18) plays a more important role than the first expansion in the somatic growth of the embryo. In addition, the expanded chorion present by stage 17 will cushion the developing embryo from external mechanical stimulation.

\section{Acknowledgments}

We express our sincere thanks to the research staff of Instituto Nacional de Investigación y Desarrollo Pes- quero (INIDEP) and the captain, officers, and crew of $\mathrm{R} / \mathrm{V}$ Oca Balda. This study was a cooperative project funded by Japan International Cooperation Agency (JICA) and INIDEP. We thank J. Bower from Hokkaido University for valuable comments, which improved the manuscript.

\section{References}

1. Arnold, J. M. \& O’Dor, R. (1990) In vitro fertilization and embryonic development of oceanic squid. J. Cephalopod Biol., 1, 21-36.

2. Boletzky, S. von, Rowe, L. \& Aroles, L. (1973) Spawning and development of the eggs, in the laboratory, of Illex coindetii. The Veliger, 15, 257-258.

3. Bower, J. R., et al. (1999) Transport of the ommastrephid squid under cold-water anesthesia. Aquaculture, 170, 127130.

4. Brunetti, N. (1990) Escala para la identificacion de estadios de madurez sexual del calamar (Illex argentinus). Frente Maritimo, 7, 45-51.

5. Brunetti, N. E. et al. (1998) Fishery biology and life history of Illex argentinus. In Proceedings Int. Symp. on Large Pelagic Squids. ed. Okutani, T., Japan Marine Fishery Resources Research Center, Tokyo, Japan, 217-231.

6. Crawford, K. (2000) The role of microtubules during blastdisk formation of the squid, Loligo pealeii. Biol. Bull., 199, 207-208.

7. Crawford, K. (2002). Culture method for in vitro fertilization to hatching of the squid, Loligo pealeii. Biol. Bull., 203, 216-217.

8. Ikeda, Y. \& Sakaurai, Y. (2004) Note on fertilization capacity of spermatozoa stored in spermatangium: A possible extra sperm storage site in the Japanese common squid Todarodes pacificus. Suisanzhoshoku, 52, 101-102.

9. Ikeda, Y., Sakurai, Y. \& Shimazaki, K. (1991) Development of male reproductive organs during sexual maturation in the Japanese common squid Todarodes pacificus. Nippon suisan gakkaishi, 57, 2237-2241.

10. Ikeda, Y., Sakurai, Y. \& Shimazaki, K. (1993) Fertilization capacity of squid (Todarodes pacificus) spermatozoa collected from various sperm storage sites, with special reference to the role of gelatinous substance from oviducal gland in fertilization and embryonic development. Invert. Reprodn. Dev., 23, 39-44.

11. Ikeda, Y. \& Shimazaki, K. (1995) Does nidamental gland jelly induce the formation of perivitelline space at fertilization in the squid Todarodes pacificus? J. Mar. Biol. Ass. U.K., 78, 495-497.

12. Mann, T., Martin, A.W. \& Thiersh, J.B. (1981) Changes in the spermatophoric plasma during spermatophore development and during the spermatophoric reaction in the giant octopus of the north pacific, Octopus dofleini martini. Mar. Biol., 63, 121-127.

13. Morisawa, M. (1988) Studies on the initiation mechanism of sperm motility: On reviewing the past and previewing the future. Seibutsu butsuri, 28, 141-147 [In Japanese with English abstract].

14. O'Dor, R. K. et al. (1982) Embryonic development of the 
squid, Illex illecebrosus, and effect of temperature on development rates. J. Northw. Atl. Fish. Sci., 3, 41-45.

15. Rodhouse, P. G. \& Hatfield, E.M.C. (1990) Dynamics of growth and maturation in the cephalopod Illex argentinus de Castellanos, 1960 (Teuthoidea: Ommastrephidae). Phil. Trans. R. Soc. Lond. B, 329, 229-241.

16. Sakai, M. \& Brunetti, N. (1997) Preliminary experiments on artificial insemination of the Argentine shortfin squid Illex argentinus. Fish. Sci., 63, 664-667.

17. Sakai, M. et al. (1998) Embryonic development and hatchlings of Illex argentinus derived from artificial fertilization. In: Payne A. I. L., Lipinski, M. R., Clarke, M. R., Compagno, M. A. C. (eds), Cephalopod Biodiversity, Ecology and Evolution. S. Afr. J. Mar. Sci., 20, 255-265.

18. Sakai, M. et al. (2004) Interpretation of statolith microstructure in rearing hatchling paralarvae of the squid Illex argentinus. Mar. Fresh. Res., 55, 403-413.

19. Sakurai, Y. et al. (1995) Artificial fertilization and development through hatching in the oceanic squids Ommastrephes bartramii and Sthenoteuthis oualaniensis (Ce- phalopoda: Ommastrephidae). The Veliger, 38, 185-191.

20. Sakurai, Y. et al. (1996) Effect of temperature on development and survival of Todarodes pacificus embryos and paralarvae. Amer. Malacol. Bull., 13, 89-95.

21. Schuldt, M. (1979) Contribución al conocimiento del ciclo reproductor de Illex argentinus. Com. Invest. Cient. Pesca, Monografía, 10, 1-110.

22. Staaf, D. J. et al. (2008) Natural egg mass deposition by the Humboldt squid (Dosidicus gigas) in the Gulf of California and characteristics of hatchlings and paralarvae. J. Mar. Biol. Ass. U. K., 88, 759-770.

23. Watanabe, K. et al. (1996) Development of the ommastrephid squid Todarodes pacificus, from fertilized egg to rhynchoteuthion paralarva. Amer. Malacol. Bull., 13, 7388.

24. Yatsu, A., Tafur, R. \& Maravi, C. (1999) Embryos and rhynchoteuthion paralarvae of the jumbo flying squid $D o$ sidicus gigas (Cephalopoda) obtained through artificial fertilization from Peruvian waters. Fish. Sci., 65, 904908. 